\title{
Tracer Study : Melacak Jejak Lulusan FKM UI (Hasil Study Kualitatif Tracer Sarjana Kesehatan Masyarakat FKM UI 2006)
}

\author{
Ahmad Syafiq* Sandra Fikawati***
}

\begin{abstract}
Abstrak
Salah satu indikator penting keberhasilan pendidikan tinggi adalah sumbangsih lulusannya dalam masyarakat dan pembangunan. Tracer study dapat menyediakan informasi mengenai sumbangsih dan keterlibatan alumni di masyarakat termasuk dinamika di dunia kerja. Fakultas Kesehatan Masyarakat UI (FKMUI) sudah melaksanakan tracer study kuantitatif pada tahun 2003 yang menginformasikan beberapa aspek terkait dengan lulusan dan keberadaannya di dunia kerja. Penelitian ini merupakan tracer study kualitatif untuk melengkapi gambaran yang diperoleh pada tracer study pertama tersebut dan mencoba menggali lebih dalam informasi mengenai pengalaman pembelajaran di FKMUI, pengalaman bekerja, dan kepuasan lulusan dan pengguna lulusan terhadap pendidikan di FKMUI. Wawancara mendalam dilakukan terhadap 24 informan yang dibagi menjadi empat kelompok institusi kerja yaitu pemerintahan, sector swasta/industri, LSM, dan lembaga pendidikan tinggi. Subyek dilacak secara multi moda dan data dianalisis berdasarkan tema utama penelitian. Hasil penelitian menunjukkan bahwa pembelajaran berbasis lapangan dipersepsi sebagai pengalaman belajar yang paling penting dan bahwa soft-skill adalah keterampilan yang sangat dihargai dan relevan di dunia kerja nyata. Penelitian ini juga mengungkap bahwa pada umumnya lulusan dan pengguna lulusan merasa puas dengan pendidikan di FKMUI.
\end{abstract}

Kata kunci: Tracer study, lulusan, soft-skill

\begin{abstract}
One important indicator of the success of higher education is the contribution of its alumni in the community and development. Tracer study provides information on alumni contribution and involvement in the community including working and employment dynamics. Faculty of Public Health University of Indonesia (FPHUI) has conducted a quantitative tracer study in 2003 which informed selected aspects related to alumni and their existence in employment world. This study is a qualitative tracer study to complement the first tracer study and aimed at digging further information on learning experience in FPHUI, working experience, and alumni and user's satisfaction on education in FPHUI. In-depth interviewed were conducted to 24 informants which divided into 4 groups of institution (government, private sector/industry, non government organization and higher education institutions). Subjects were traced in a multimode way and data was analyzed based on the study main theme. Study exhibits that field-based learning is perceived as the most important learning experience and soft-skill is highly appreciated and most relevant in the real work situation. The study also found that most users and alumni are satisfied with education in FPHUI.
\end{abstract}

Key words: Tracer study, alumni, soft-skill

*Staf Pengajar Departemen Gizi Fakultas Kesehatan Masyarakat Universitas Indonesia, ** Manajer Career Development Center Universitas Indonesia 
Salah satu penilaian keberhasilan pendidikan tinggi adalah kiprah lulusannya dalam mengamalkan keilmuan yang diperoleh selama menuntut ilmu. Kesesuaian peran dan kiprah alumni di masyarakat dapat digunakan untuk mengukur keberhasilan mencetak Sumber Daya Manusia (SDM) dan juga dapat memberikan input bagi pengembangan dan perbaikan kualitas pendidikan. Fakultas Kesehatan Masyarakat Universitas Indonesia (FKM UI) sebagai institusi pendidikan tinggi telah mencetak SDM Sarjana dan Pascasarjana dalam bidang Kesehatan Masyarakat dalam kurun waktu periode 1989-2005 sejumlah 686 lulusan Sarjana dan 3.403 lulusan pascasarjana yang kini telah terjun di masyarakat untuk mengamalkan keilmuan dan keterampilan yang diperoleh selama mengenyam pendidikan di FKM UI.

Kemajuan institusi pendidikan direfleksikan melalui keberhasilan peserta didik dalam memberikan kontribusi keilmuan dan keterampilan dalam kemajuan masyarakat. Tracer study adalah suatu studi yang dilakukan oleh institusi perguruan tinggi untuk melacak jejak lulusannya dan mengukur berbagai indikator keberadaan (eksistensi) dan peran alumni dalam dunia kerjanya. Melalui penyelenggaraan suatu tracer study institusi penyelenggara pendidikan tinggi mendapatkan gambaran keberhasilan atau kegagalan kinerja pendidikan yang diselenggarakannya.

FKMUI telah menyelenggarakan Tracer Study untuk pertama kalinya pada tahun 2003. ${ }^{1}$ Tracer Study I tersebut mencakup lulusan SKM reguler tahun 1993 sampai tahun 2002 yang saat itu berjumlah 422 orang. Jumlah keseluruhan responden yang berhasil dilacak (response rate) adalah 262 orang atau 62,1\%. Walaupun FKMUI memiliki banyak program studi namun SKM reguler merupakan target utama dari pelaksanaan tracer study di FKMUI karena program studi ini merupakan inti berdirinya suatu fakultas.

Hasil Tracer Study I menunjukkan bahwa pada umumnya lulusan tahun 1993 sampai tahun 1997 hampir seluruhnya telah memperoleh pekerjaan, sedangkan tahun 1998 sampai tahun 2002 masih ada sejumlah lulusan yang belum mendapatkan pekerjaan. Berdasarkan studi tersebut juga diketahui bahwa rata-rata lama tunggu lulusan adalah 7 bulan.

Terdapat $19,1 \%$ responden yang melanjutkan studi ke jenjang lebih tinggi. Lebih dari separuh lulusan $(58,8 \%)$ bersedia ditempatkan untuk bekerja di daerah. Lebih dari $50 \%$ responden dari setiap peminatan pernah berpindah kerja kecuali peminatan AKK $(31,3 \%)$ dan Biostatistik $(26,7 \%)$. Terjadi peningkatan kepuasan kerja dari pekerjaan pertama $(39,8 \%)$ ke pekerjaan terakhir $(63,3 \%)$. Sejumlah $87,4 \%$ responden menyatakan telah mengetahui prosedur melamar pekerjaan dan hampir semua responden menyatakan perlu dibentuk job information center sebagai wadah pemberian informasi mengenai dunia kerja. ${ }^{1}$

Berdasarkan evaluasi dan kajian terhadap referensi mutakhir di bidang tracer study, ada beberapa aspek yang belum tercakup dalam Tracer Study I seperti persepsi pengguna lulusan terhadap kompetensi lulusan, persepsi lulusan mengenai relevansi learning experience di FKMUI dan kompetensi di dunia kerja, serta kepuasan pengguna terhadap kualitas pembelajaran di FKMUI. Tracer Study II ini merupakan suatu studi kualitatif yang dilakukan untuk menelusuri lebih lanjut informasi perkembangan pencarian kerja lulusan SKM FKMUI serta aspek-aspek tersebut di atas. Tujuan dari studi ini adalah untuk mendapatkan data dan informasi mengenai pengalaman pembelajaran serta kepuasan pengguna dan lulusan yang belum tercakup dalam Tracer Study I.

\section{Metode}

Disain penelitian yang digunakan adalah studi kualitatif dengan menggunakan indepth interview.

Subjek penelitian adalah lulusan dan pengguna lulusan sarjana FKM UI. Subjek lulusan dipilih secara purposif dari lulusan tahun 2000-2004 dan memiliki masa kerja minimal satu tahun, dengan pertimbangan bahwa masa

Gambar 1. Tren Lulusan Tahun 1993-2002 yang Sudah Bekerja Berdasarkan Tahun Lulus

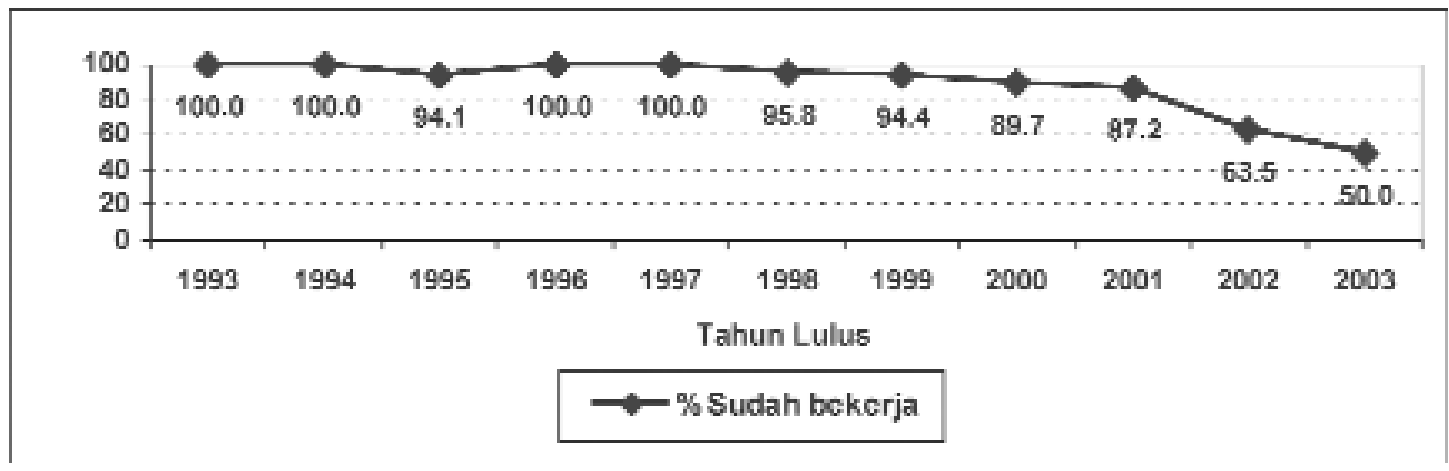

Sumber: Fikawati dan Syafiq. 2003. Tracer Study Sarjana Reguler FKMUI 
Tabel 1. Nama Instansi dan Asal Peminatan Informan

\begin{tabular}{|c|c|c|c|c|}
\hline \multicolumn{5}{|c|}{ Instansi pemerintah } \\
\hline Nama instansi & \multicolumn{2}{|c|}{ Departemen Kesehatan Pusat } & \multicolumn{2}{|c|}{ Dinas Kesehatan Kota Depok } \\
\hline Nama & Informan A & Informan B & Informan C & Informan D \\
\hline Peminatan & Epidemiologi & KKK & Epidemiologi & PKIP \\
\hline Nama atasan & \multicolumn{2}{|c|}{ Atasan 1} & \multicolumn{2}{|c|}{ Atasan 2} \\
\hline \multicolumn{5}{|c|}{ Instansi non pemerintah (swasta) } \\
\hline Nama instansi & \multicolumn{2}{|c|}{ Astra Honda Motor } & \multicolumn{2}{|c|}{ Transportasi Gas Indonesia } \\
\hline Nama & Informan E & Informan F & Informan $\mathrm{G}$ & Informan $\mathrm{H}$ \\
\hline Peminatan & KKK & Kesling & KKK & Kesling \\
\hline Nama atasan & \multicolumn{2}{|c|}{ Atasan 3} & \multicolumn{2}{|c|}{ Atasan 4} \\
\hline \multicolumn{5}{|c|}{ Instansi LSM/Lembaga Penelitian } \\
\hline Nama instansi & \multicolumn{2}{|c|}{ Yayasan Pelita Ilmu } & \multicolumn{2}{|c|}{ World Vision Indonesia } \\
\hline Nama & Informan I & Informan J & Informan $\mathrm{K}$ & $\overline{\text { Informan L }}$ \\
\hline Peminatan & Epidemiologi & KKK & $\mathrm{K} 3$ & Biostatistik \\
\hline Nama atasan & \multicolumn{2}{|c|}{ Atasan 5} & \multicolumn{2}{|c|}{ Atasan 6} \\
\hline \multicolumn{5}{|c|}{ Instansi Perguruan Tinggi } \\
\hline Nama instansi & \multicolumn{2}{|c|}{ STIKIM } & \multicolumn{2}{|c|}{ Universitas Muhammadiyah Jakarta } \\
\hline Nama & Informan M & Informan $\mathrm{N}$ & InformanO & Informan P \\
\hline Peminatan & KKK & Biostatistik & Gizi Kesmas & Biostatistik \\
\hline Nama atasan & \multicolumn{2}{|c|}{ Atasan 7} & \multicolumn{2}{|c|}{ Atasan 8} \\
\hline
\end{tabular}

kerja satu tahun sudah dapat memberikan deskripsi cukup mendalam mengenai pekerjaannya. Subjek pengguna lulusan, dipilih atasan dari lulusan yang terpilih dan bersedia diwawancara. Lulusan dikelompokkan berdasarkan 4 kelompok institusi tempat bekerja yang diperoleh dari hasil Tracer Study I, yaitu instansi pemerintah, swasta/industri (manufaktur dan jasa), LSM/lembaga penelitian, dan perguruan tinggi (negeri/swasta). Dalam rangka menjaga keketatan (rigour) penelitian dan memungkinkan triangulasi sebagai bagian dari upaya penjagaan kualitas data dalam penelitian kualitatif, untuk masing-masing kelompok institusi pekerjaan dipilih minimal dua institusi dan di setiap jenis institusi harus ada minimal 2 orang lulusan dan 1 orang atasan yang bersedia diwawancara. Sebagai implikasi dari penerapan asas rigour dan triangulasi di atas, dari seluruh alumni yang terdata di Tracer Study I, yang memenuhi kriteria sesuai dengan struktur pengambilan subjek di atas ada sejumlah 24 orang. Pengumpulan data dilakukan menggunakan in-depth interview dengan pedoman wawancara yang sudah disusun dan diujicoba. Subjek dilacak secara multi-moda dan data dianalisis berdasarkan tema utama penelitian. Penelitian dilakukan pada bulan September-November 2006.

\section{Hasil}

Tabel $1 \mathrm{di}$ atas menunjukkan gambaran instansi tempat informan bekerja beserta asal peminatan informan saat kuliah di FKMUI.

Seperti dapat dilihat pada tabel di atas, di instansi pemerintahan (Departemen Kesehatan Pusat dan Dinas
Kesehatan Kota Depok) informan berasal dari peminatan Epidemiologi, Keselamatan dan Kesehatan Kerja (K3), dan Pendidikan Kesehatan dan Ilmu Perilaku (PKIP). Di instansi non pemerintah (Astra Honda Motor dan Transportasi Gas Indonesia) asal peminatan informan kurang beragam hanya K3 dan Kesehatan Lingkungan (Kesling). Sedang di instansi lainnya (LSM/lembaga penelitian dan perguruan tinggi) informan berasal dari Epidemiologi, Administrasi Kesehatan dan Kebijakan (AKK), Biostatistika dan Kependudukan (Biostat), dan K3.

\section{Pencarian Kerja Setelah Lulus untuk Strata 1}

Modus pencarian kerja yang dilakukan oleh lulusan Strata 1 bersifat heterogen, yaitu dengan memanfaatkan semua cara pencarian kerja seperti iklan koran, informasi melalu teman, melalui dosen, dan informasi dari papan pengumuman di kampus. Meski demikian informan juga umumnya ditawari pekerjaan, bahkan ada yang ditawari pekerjaan sebelum lulus dari FKMUI. Hampir semua responden tidak mengalami kesulitan dalam pencarian kerja pertama. Dari matriks tema utama diketahui bahwa pencarian kerja untuk pekerjaan pertama terutama melalui networking baik jaringan pertemanan maupun dengan senior dan dosen.

Dalam kaitannya dengan networking dengan dosen, terungkap bahwa banyak informan yang mengawali karir pertamanya dengan ikut dalam kegiatan pendidikan, penelitian maupun layanan masyarakat yang dikerjakan oleh staf pengajar FKMUI. Di satu sisi, situasi ini mencerminkan kedekatan hubungan kerja antara dosen dan 
mahasiswanya yang dipercaya untuk membantu aktifitas akademik baik itu penelitian maupun asisten akademik. Di sisi lain, hubungan dalam rangka kerja (work relationship) ini, sebagai lanjutan dari hubungan dalam rangka pendidikan (education relationship) memberi manfaat bagi lulusan dengan cara memberikan kesempatan transisi dari dunia pendidikan ke dunia kerja.

Berikut disajikan beberapa kutipan informan dari berbagai departemen yang berbeda sehubungan dengan upaya pencarian pekerjaan melalui dosen baik sebagai asisten maupun melalui keikutsertaan dalam proyek-proyek penelitian.

“.... kurang tertarik lewat koran, karena paling jadi enumerator, sedangkan aku tertariknya ke arah data. Jadi aku mending koneksi ke dosen..." (Lulusan S1 tahun 2003, Departemen Biostatistik)

".... Asisten dosen di jurusan Gizi, kemudian kerja dengan Pak (nama dosen) jadi asisten selama setahun, kemudian direkomendasikan jadi staf ke UMJ...." (Lulusan S1 tahun 2000, Departemen Gizi Kesmas)

"... Sejak awal saya kan ikutan proyek.... biasanya kan anak-anak FKM kebanyakan ikut proyek. Kemudian bertemulah saya dengan Pak (nama dosen), ditawari untuk kerja di STIKIM, sehingga dari awal saya tidak nganggur... Sebelum lulus saya sudah minat dengan pendekatan proyek-proyek itu tadi..." (Lulusan S1 tahun 1999, Departemen K3).

Hampir semua informan pernah mengalami pindah pekerjaan. Meskipun pindah pekerjaan itu terjadi dalam satu instansi tetap dianggap sebagai pindah kerja karena job description yang berbeda. Pada umumnya informan merasa kurang atau tidak sesuai dengan pekerjaan pertamanya dan berencana untuk pindah. Sedangkan di pekerjaan terakhir umumnya informan merasa betah dan cukup puas serta tidak berencana pindah meskipun dilihat dari segi kesesuaian dengan latar belakang pendidikan tidak selalu pekerjaan yang terakhir ini juga sesuai. Tingginya mobilitas pekerjaan ini sebenarnya sudah terungkap dalam Tracer Study I yang menyebutkan bahwa sejumlah $44 \%$ responden pernah berpindah kerja dan lebih dari 30\% pernah berpindah kerja minimal 2 kali. ${ }^{1}$ Alasan berpindah kerja umumnya terkait dengan prospek karir yang dianggap kurang cerah atau pendapatan yang dirasakan kurang seperti tampak dalam kutipan di bawah ini.

“........ karena itu belum mantap bu. Saya cari kerjaan yang mantap, ya istilahnya... yang bisa menjanjikan gitu...." (Lulusan S1 tahun 2000, Departemen Biostatistik)

“.... Bosnya galak..., terus untuk karir kurang, kurang lebih itu lah.... jadi yang di keluarkan sama yang saya dapatkan tidak sebanding.. (Lulusan S1 tahun 2003, Departemen K3)

“... jadi asdos, suasana kerja juga enak tetapi untuk income kurang...” (Lulusan S1 tahun 2002, Departemen KL)

\section{Pengalaman Pembelajaran di FKMUI}

Kontribusi penting dari pengalaman belajar di FKMUI berdasarkan jawaban informan dapat dipilah menjadi dua bagian besar yaitu pertama, kontribusi terkait substansi keilmuan yang diperoleh melalui kuliah di kelas, dan kedua kontribusi yang terkait dengan pola pikir dan kualifikasi softskill yang diperoleh di luar kelas misalnya dalam pergaulan dengan teman, senior dan dosen, serta pengalaman organisasi dan belajar di lapangan. Bahkan bagi sebagian informan, kontribusi terbesar dari pengalaman belajar di FKMUI bukanlah pada pembelajaran di dalam kelas tetapi justru diperoleh dari pengalaman belajar di luar kelas seperti Praktek Belajar Lapangan (PBL) dan magang, serta terlibat dalam kegiatan organisasi kemahasiswaan. Berikut beberapa kutipan informan sehubungan dengan pengalaman pembelajaran di FKMUI dan tingginya apresiasi informan terhadap kegiatan dan pengalaman belajar di lapangan.

“..... kalau magang itu nggak cukup sebulan. Tiga bulan lah minimal, dan kita kalau magang kan cuma dudukduduk aja kan? Memang kita akan dilibatkan? Nggak kan? Seharusnya fakultas memberikan kerjasama yang baik gitu, kalau mahasiswa magang tuh dikasih apalah gitu, jadi nggak disuruh datang dengan kasih tangan kosong datang ...." (Lulusan S1 tahun 2001, Departemen Epidemiologi)

“..Iya, pokoknya pelajaran yang bersifat praktis, praktek lapangan atau masyarakat, itulah yang sangat berkontribusi. .. jadi diperbanyak untuk ke lapangannya kali ya. Maksudnya...misalkan PBL diperbagus, lebih ini lagi...gitu..." (Lulusan S1 tahun 2003, Departemen Biostatistik)

"...di FKM itu yang menurut saya sangat berharga adalah pengalaman-pengalaman penelitian ke masyarakat. Dulu kan sering diajak dosen, karena selain kuliah juga sering penelitian ke lapangan. Itu berharga karena kita langsung melihat keadaan di lapangan, ketemu tokoh masyarakat... jadi kita harus lebih banyak belajar lagi mengenai masyarakat..." (Lulusan S1 tahun 1994, Departemen Epidemiologi)

".....saya senang aktif di organisasi, jadi selain mata kuliah yang banyak membentuk adalah aktivitas di kampus seperti senat fakultas, senat universitas......." (Lulusan S1 tahun 1994, Departemen K3)

Kutipan-kutipan di atas juga mencerminkan bahwa menurut informan, pelajaran-pelajaran yang dianggap relevan dengan dunia kerja meliputi berbagai pelajaran yang merupakan ilmu alat (tools) dalam kesehatan masyarakat seperti Biostatistika, Perencanaan dan Evaluasi, Manajemen, dan Komputer sementara itu pelajaran seperti Anatomi Fisiologi dan Parasitologi dianggap kurang relevan dan terlalu medis. Mata kuliah yang disebutkan sebagai relevan adalah mata kuliah yang dapat diaplikasikan secara langsung di dunia kerja. Mengenai mata kuliah yang relevan dan tidak relevan, berikut kutipan-kutipan langsung dari informan.

“....cuma yang betul-betul kepakai yang sifatnya skills. 
Contohnya kayak dulu waktu belajar Epi-info/SPSS, itu sampai sekarang masih kepakai..." (Lulusan S1 tahun 1998, Departemen K3)

".... lebih ke ini sih ...metlit, pengolahan data, analisa data, kritik sosial, semua mata kuliah biostatistik itu kayaknya yang relevan banget...." (Lulusan S1 tahun 2003, Departemen Biostatistik)

"..Yang nggak relevan, yang medis, yang terlalu medis...” (Lulusan S1 1997, Departemen PKIP)

Meskipun sebagian besar informan menyatakan puas dengan pembelajaran di FKMUI, ada juga informan yang menyatakan kurang puas atau tidak puas karena ketidaksesuaian antara kuliah yang didapat dengan pekerjaan. Sementara itu informan yang lain menyatakan ketidakpuasan dalam kaitannya dengan kualitas pembelajaran yaitu kuliah yang tidak sesuai jadwal, keterlambatan dosen atau materi kuliah yang kurang up to date. Kutipan informan di bawah ini kiranya mewakili apa yang dikeluhkan tersebut.

“.... Kalau dosen jangan apa ya namanya, ya sebagai dosen kan seharusnya nambah terus ilmunya. Jangan dipake transparan dari jaman kapan, itu dipake terus-terusan. Kadang-kadang ampe kuning, ya paling nggak seringseringlah gitu kayak dari internet, kayak gitu-gitu..." (Lulusan S1 tahun 2001, Departemen Epidemiologi)

“.... Saya rasa masih kurang di kehadiran dosennya, kalau dulu jaman saya memang terkadang ada yang nggak datang, mungkin datang kalau perlu saja.... Perbandingan antara dosen dengan mahasiswa jangan terlalu besar lah, karena pembelajaran jadi tidak efektif. Kemudian apa ya...mungkin dosen-dosennya perlu ditingkatkan lagi ya, supaya ilmu pengetahuan yang dimiliki lebih tinggi beberapa tingkat dari mahasiswanya gitu lho......" (Lulusan S1 tahun 2003, Departemen K3)

“... Mungkin dosennya lebih memberikan contoh yang aplikatif, jangan mengambang, atau hanya memberikan teori-teori..." (Lulusan S1 tahun 2003, Departemen Biostatistik)

Erat kaitannya dengan persepsi terhadap relevansi mata kuliah, persepsi lulusan S1 terhadap kompetensi memasuki dunia kerja setelah lulus umumnya kurang merasa kompeten dan kurang yakin terhadap kemampuan dirinya. Sebagian informan menganggap bahwa FKM itu kurang memiliki ke"khas"an, dan bersifat terlalu umum dibandingkan dengan disiplin ilmu lain. Data dari Tracer Study I menunjukkan $78,2 \%$ responden menginginkan keterampilan yang lebih spesifik. ${ }^{1}$ Berikut beberapa kutipan informan sehubungan dengan kompetensi.

“.... waktu itu jujur saja ya, belum. Saya rasa FKM itu nggak punya senjata, senjatanya itu apa? Misalnya dokter itu bawanya stetoskop gitu kan, atau apa tensimeter gitu. Aku bawanya apa? Ilmunya cuma di surface saja (Lulusan S1 tahun 1997, Departemen PKIP)

“.....belum ya. Jadi saya rasa memang belum begitu ku- at untuk kompeten saya itu.... Teorinya tahu, tapi untuk penerapannya nggak ada gambaran gitu lho..." (Lulusan S1 tahun 2003, Departemen K3)

Di era globalisasi, kemampuan menembus batas-batas disiplin merupakan kemampuan dari seorang sarjana yang penting dan sangat dihargai. ${ }^{2,3}$ Jika dicermati memang salah satu keunggulan dari pembelajaran di FKMUI adalah sifat dan karakter khas Kesehatan Masyarakat sebagai disiplin ilmu yang multidisiplin. Kemampuan multidisiplin dan lintas disiplin merupakan aset penting bagi keterampilan komunikasi dan kerja dalam kelompok. Tetapi kesadaran mengenai pentingnya multidisiplinaritas nampak masih kurang di kalangan mahasiswa dan lulusan yang menghendaki keterampilan dan kemampuan yang lebih monodisiplin dan spesifik dibanding multidisiplin dan generik.

"...Dari segi keilmuan saya tidak merasa yakin dan tidak merasa siap, karena waktu itu saya merasa bidang keilmuan yang saya dapat rasanya nggak matang..." (Lulusan S1 tahun 1997, Departemen K3)

"..... Ya, itu, karena dulu kata senior kita dapat di kampus itu ilmu, atau keadaan ideal, tapi ketika kerja tuh beda, saya juga masih bingung, jadi ketika masuk sini saya nggak PD apakah ilmu itu bisa diterapkan...” (Lulusan S1 tahun 2004, Departemen KL)

Meski demikian informan juga mengakui bahwa bagaimanapun kuliah di FKM telah membekalinya dengan pola pikir yang sangat diperlukan di dunia kerja seperti tercermin pada kutipan-kutipan berikut ini.

“... Kalau menurut saya S1 itu mengembangkan kemampuan berpikir, itu saja yang saya ambil. Kalau kita pendidikannya lebih tinggi, kemampuan nalar kita lebih luas lah gitu. Ya mungkin yang dipake disini, di dinas ini mungkin kebanyakan pelajaran manajemen, karna saya di perencanaan program.." (Lulusan S1 1997, Departemen PKIP)

“... awalnya aku berpikir kalau nanti kita kerja di dunia yang bukan FKM kita tetap akan bisa karena yang dipelajari di FKM kan cara berpikir dan itu yang nantinya berguna dan digunakan dalam dunia kerja. Menurutku sih percaya diri aja, yang penting kan berani, kalau kita tidak pernah mencoba kita ngga akan pernah tahu kita bisa atau tidak. Yang penting berani mencoba dan berani salah..." (Lulusan S1 tahun 2000, Departemen Biostatistik)

Hal ini sejalan dengan observasi Teichler,2,4 Yorke dan Knight ${ }^{5}$ mengenai dinamika hubungan antara pendidikan tinggi dan dunia kerja yang sedang mengalami pergeseranpergeseran penting, terutama terkait dengan jurang antara outcome pendidikan tinggi dan tuntutan kompetensi di dunia kerja. Beberapa pergeseran penting yang terjadi meliputi terjadinya peningkatan pengangguran terdidik baik pengangguran terbuka maupun terselubung sebagai akibat dari massifikasi pendidikan tinggi, berubahnya struktur sosio-ekonomi dan politik global yang mempengaruhi pasar dunia kerja dan perkembangan ilmu pengetahuan dan 
teknologi yang pesat sehingga menyebabkan terjadinya bebagai perubahan-perubahan mendasar dalam hal kualifikasi, kompetensi, dan persyaratan untuk memasuki dunia kerja.

Lebih lanjut Teichler ${ }^{2}$ mengungkap beberapa fenomena menarik belakangan ini mencakup:

1. Kemampuan mengatasi ketidakpastian (uncertainty) merupakan kunci untuk bertahan di dunia kerja

2. Pengetahuan yang spesifik memiliki kecenderungan cepat menjadi usang (obsolete), di sisi lain keterampilan umum yang bisa digunakan untuk mengatasi masalah dalam konteks professional dan ketidakpastian pasar kerja harus menjadi dasar sistem belajar mengajar di pendidikan tinggi.

3. Persyaratan dunia kerja dewasa ini menunjukkan harmoni antara ekonomi neoliberal yang global dan peningkatan tanggung jawab sosial serta solidaritas secara bersamaan.

4. Bergesernya anggapan bahwa pendidikan tinggi mempersiapkan seseorang untuk bekerja menjadi mempersiapkan seseorang untuk hidup lebih baik, karena kompetensi yang dibutuhkan untuk bekerja saat ini begitu luas dan kompleks sehingga mempunyai hubungan langsung dengan kebutuhan untuk kehidupan itu sendiri

5. Persyaratan kerja yang baru tampak semakin universal. Paul dan Murdoch (1992) menjelaskan menghadapi dunia kerja, seorang lulusan perguruan tinggi harus dilengkapi dengan kualifikasi berikut ini agar dapat bertahan dan unggul dalam kompetisi:

1. Pengetahuan umum dan penguasaan bahasa Inggris

2. Keterampilan komunikasi meliputi penguasaan komputer dan internet, presentasi audiovisual, dan alat-alat komunikasi lain

3. Keterampilan personal meliputi kemandirian, kemampuan komunikasi dan kemampuan mendengar, keberanian, semangat dan kemampuan kerjasama dalam tim, inisiatif, dan keterbukaan

4. Fleksibilitas dan motivasi untuk maju yaitu kemampuan beradaptasi sesuai perubahan waktu dan lingkungan serta keinginan untuk maju sebagai pimpinan.

Dalam hubungannya dengan ketidakpuasan terkait dengan kesenjangan antara substansi yang diperoleh dari kuliah dengan kompetensi yang dibutuhkan di dunia kerja, Kellerman dan Sagmeister 6 menyatakan bahwa hal ini dapat disebabkan oleh pertama, kenyataan bahwa sistem pendidikan tinggi memiliki jarak dengan dunia kerja sehingga indikator-indikator keberhasilan studi tidak dapat mengantisipasi kompetensi lulusan yang diperlukan untuk bekerja (under qualification), atau kedua, dunia kerja mungkin tidak diorganisasikan dengan baik sehingga keterampilan lulusan tidak dapat dimanfaatkan secara efisien (under utilization), atau kemungkinan ketiga adalah lulusan memiliki kemampuan yang melebihi syarat kompetensi di dunia kerja (over qualification).

\section{Pendapat Atasan Mengenai Bawahan Lulusan FKMUI}

Semua atasan menyatakan puas atau sangat puas dengan bawahan lulusan FKMUI. Dari segi kompetensi, lulusan FKMUI dianggap memiliki kompetensi yang baik dalam arti bisa diajak diskusi, tidak perlu banyak pengarahan, daya tangkap cepat, hasil kerja membanggakan, dan lebih fokus. Jika dibandingkan dengan lulusan non FKMUI hampir sama saja, tetapi ada atasan yang menilai bahwa lulusan FKMUI lebih mudah berinteraksi dengan rekan kerja dari berbagai latar belakang dan juga lebih mudah mengerti jika diberikan tugas.

"....... di UI, mhs dididik untuk selalu diskusi, itu manfaat sekali..." (Atasan lulusan S1, Instansi Pemerintah)

"... lulusan FKMUI itu bisa langsung kerja tanpa perlu banyak pengarahan. Mereka cepat.." (Atasan lulusan S1, Instansi Pemerintah)

“....... bagus, terutama yang saat di mahasiswa nya aktif berorganisasi..." (Atasan lulusan S1, Instansi Perguruan Tinggi)

"... lebih dari lulusan lain. Daya tangkap lebih cepat. Kalo yang lain disuruh agak harus berkali-kali..." (Atasan lulusan S1, Instansi Perguruan Tinggi)

Di samping kelebihan dari lulusan FKMUI, informan atasan memberikan penilaian juga mengenai aspek yang harus ditingkatkan oleh bawahan lulusan FKMUI termasuk dari segi perencanaan, pengolahan data dan statistik, pengalaman riil di lapangan, aspek kepribadian dan soft-skill (keterampilan lunak seperti komunikasi, toleransi, etika, budi pekerti, dan kualitas personal lain) lainnya seperti keaktifan dan inisiatif. Semua atasan menyatakan puas atau sangat puas dengan bawahan lulusan FKMUI. Temuan ini semakin menegaskan pentingnya kemampuan yang bersifat multidisiplin serta pentingnya soft-skill di dunia kerja. Berikut kutipan dari atasan lulusan S1 mengenai usulan dan perbaikan bagi lulusan S1 FKMUI.

“....... Cuma kalau diminta masukan adalah, lebih ke aktif dan punya inisiatif ya..." (Atasan lulusan S1, Instansi Swasta)

"...Perbanyak riset yang membiasakan mahasiswa terlibat di dunia kerja dan tingkatkan bekerja sama dengan industri..." (Atasan lulusan S1, Instansi Swasta)

“...terus dibekali itu tadi, entrepreneurship itu penting. Dikasih banyak kegiatan di luar kuliah, semakin banyak kegiatan semakin bagus..." (Atasan lulusan S1, Instansi Perguruan Tinggi)

“...pengetahuannya harus bisa dia hubungkan dengan dunia praktek. Saya sering menemukan teorinya begini, prakteknya begini tapi dia tidak bisa mendapatkan korelasi.... Daya analisis kurang, tapi pengetahuan saya kira cukup...." (Atasan lulusan S1, Instansi Swasta)

Teichler ${ }^{4,7}$ menyampaikan hasil survei di Eropa yang menunjukkan bahwa terlepas dari spesialisasi pendidikannya, lulusan perguruan tinggi diharapkan dapat fleksibel mampu dan mau memberikan kontribusi terhadap inovasi; 
mampu mengatasi ketidakpastian; siap untuk belajar sepanjang hidup; memiliki sensitifitas sosial dan keterampilan komunikasi; mampu bekerja dalam kelompok bertanggung jawab; menyiapkan diri untuk menghadapi kompetisi internasional; memiliki pengetahuan di luar wilayah spesifik keahliannya; mengerti bagaimana cara mengkombinasikan berbagai disiplin; dan kreatif.

Dalam kaitannya dengan keberhasilan pendidikan tinggi menembus dunia kerja, Teichler ${ }^{2}$ menyebutkan 5 kriteria utama keberhasilan yaitu:

1. Transisi yang mulus dari pendidikan tinggi ke dunia kerja meliputi masa tunggu kerja yang singkat dan upaya pencarian kerja yang sederhana.

2. Rasio pengangguran yang rendah

3. Rasio pekerjaan non-reguler yang rendah

4. Kesuksesan lulusan secara vertikal dalam arti investasi pendidikan memperoleh keuntungan atau pendapatan lulusan lebih tinggi dibanding bukan lulusan atau rasio bekerja lulusan yang tinggi

5. Kesuksesan lulusan secara horizontal dalam arti hubungan yang erat antara bidang studi dan jenis pekerjaan atau tingginya utilisasi pengetahuan yang diperoleh selama pendidikan tinggi dalam pekerjaan.

Lebih lanjut Yorke dan Knight ${ }^{5}$ mengenalkan konsep employability atau kemampuan mendapatkan pekerjaan yang didefinisikan sebagai sekumpulan pencapaian (achievement) meliputi keterampilan, pemahaman, dan atribut personal yang lebih memungkinkan lulusan untuk memperoleh pekerjaan dan sukses dalam pilihan kerjanya serta memberi keuntungan bagi diri mereka sendiri, tenaga kerja, masyarakat, dan ekonomi secara keseluruhan. Selanjutnya Yorke dan Knight ${ }^{5}$ menjelaskan bahwa employability sangat terkait dengan kapabilitas seperti :

1. Mengambil tindakan yang efektif dan tepat

2. Menjelaskan apa yang ingin mereka capai

3. Hidup dan bekerja dengan yang lain

4. Dapat terus belajar baik secara individual maupun dengan yang lain dalam masyarakat yang beragam dan terus berubah.

Dengan demikian hal ini sejalan dengan usulan dari beberapa atasan agar mahasiswa FKMUI mendapat lebih banyak praktik di lapangan melalui magang dan PBL agar dapat lebih mengenal kenyataan di lapangan kerja. Disarankan agar ditingkatkan kerjasama dengan pihak pengguna lulusan dalam hal magang, PBL, dan penelitian serta penyusunan kurikulum. Juga diusulkan agar kewirausahaan bisa ditanamkan juga terhadap lulusan FKMUI.

\section{Kesimpulan dan Saran}

Pengalaman bekerja di dunia akademik FKMUI (sebagai asisten dosen, asisten peneliti, staf lapangan) merupakan pengalaman yang berharga bagi mahasiswa dan lulusan sebagai periode transisi memasuki dunia kerja di luar FKMUI. Dengan demikian disarankan untuk lebih banyak melibat- kan mahasiswa dan lulusan dalam kegiatan-kegiatan akademik dan penelitian FKMUI.

Kemampuan multidisiplin, soft-skill, dan pengalaman lapangan harus ditingkatkan dalam proses pembelajaran di FKM UI karena merupakan kemampuan penting dan dihargai tinggi oleh dunia kerja. Disarankan untuk memperbaiki dan menyempurnakan komponen-komponen tersebut melalui kegiatan seperti magang dan PBL yang disusun secara lebih sistematis, efektif, efiesien, dan melibatkan pengguna lulusan FKMUI. Demikian juga dengan struktur mata kuliah yang ada agar lebih banyak memasukkan aspek praktikal dan situasi terkini yang ada di lapangan.

Tingkat kepuasan lulusan S1 kurang baik dalam hal pengalaman pembelajaran di FKMUI, dalam arti merasa banyak mata kuliah yang tidak terpakai di dunia kerja dan merasa belum memiliki kompetensi untuk bekerja setelah lulus. Hal ini diduga erat kaitannya dengan perbedaan persepsi mengenai kompetensi sarjana dan persyaratan dunia kerja terkait dunia akademik Disarankan untuk menyamakan persepsi, pengetahuan, dan pengalaman mahasiswa S1 mengenai dunia kerja yang sesungguhnya sehingga tidak terjadi perbedaan persepsi.

Sebaliknya, dari sisi pengguna, tingkat kepuasan terhadap lulusan S1 FKMUI dapat dikatakan baik dan umumnya merasa puas dengan kinerja mereka karena dianggap memiliki kompetensi yang baik dalam arti bisa diajak diskusi, tidak perlu banyak pengarahan, daya tangkap cepat, hasil kerja membanggakan, dan lebih fokus. Meskipun demikian disarankan untuk lebih meningkatkan kemampuan kerjasama tim, kewirausahaan, dan memperbanyak pengalamanpengalaman persentuhan dengan dunia kerja.

Perbedaan tingkat kepuasan antara lulusan dan pengguna mungkin disebabkan oleh mispersepsi lulusan mengenai kemampuan yang dibutuhkan di dunia kerja yang menurut lulusan bersifat spesifik, namun dalam kenyataannya, dunia kerja membutuhkan kemampuan tinggi yang bersifat lebih generik seperti diungkapkan oleh pengguna lulusan.

\section{Daftar Pustaka}

1. Fikawati S dan A Syafiq. 2003. Tracer study: Sarjana Kesehatan Masyarakat Fakultas Kesehatan Masyarakat Universitas Indonesia Program Reguler Lulusan Tahun 1993-2002. Fakultas Kesehatan Masyarakat Universitas Indonesia.

2. Teichler U. 1999. Research on the relationship between higher education and the world of work: past achievements, problems and new challenges. Higher Education Vol 38: 169-190

3. Schomburg H. 2006. UNISTAFF training materials. ISOS-Kassel University. Kassel.

4. Teichler U. 1997. Graduate employment: challenges for the higher education in the twenty-first century. Higher Education in Europe Vol XXII No 1.

5. York M and PT Knight. 2006. Curricula for economic and social gain. Higher Education 2006 Vol 51: 565-568

6. Kellermann P and G Sagmeister. 2000. Higher education and graduate employment in Austria. European Journal of education Vol 35 No 2 June 2000.

7. Brennan J, M Kogan and U Teichler. 1996. Higher Education and Work. Jessica Kingsley Publication. London, Bristol, Pennsylvania. 